\title{
Report of a Clinical Case in Agoraphobia: The Challenge to Fly
}

\author{
Luísa Pelúcio ${ }^{1 *}$, Antonio Egídio Nardi ${ }^{1,2}$ and Michelle Levitan ${ }^{1,2}$ \\ ${ }^{1}$ Institute of Psychiatry, Federal University of Rio de Janeiro, Brazil \\ ${ }^{2}$ National Institute for Science and Technology, Federal University of Rio de Janeiro, Brazil
}

Submission: August 07, 2017; Published: August 24, 2017

*Corresponding author: Luísa Pelúcio, Institute of Psychiatry, Federal University of Rio de Janeiro-INCT Translational Medicine, R Visconde de Pirajá, 407/702-Rio de Janeiro-RJ-22410-003, Brazil, Tel: 5521-25216147; Fax: 5521-2523683; Email: luisapelucio@hotmail.com

\begin{abstract}
This is a report of a clinical case in which the patient wishes to modify dysfunctional avoidance behavior, in order to be able to confront his fears of elevators, high places and planes. The presence of activator tasks between sessions as motivation for the final objective was of significant importance. Cognitive behavior therapy was used as base methodology. It was concluded that it is an effective and tangible treatment for the agoraphobic, providing assistance and bringing success and applicability in this case [1].
\end{abstract}

Keywords: Agoraphobia; Systematic desensitization; Cognitive behavior therapy

\section{Introduction}

This study has the objective of reporting a clinical case of cognitive behavior therapy, which is short term structured therapy, focused on the resolution of problems. According to Cognitive Behavior Therapy, the therapist teaches the client to respond to negative emotional states in an adaptive way. Clients frequently describe their bodily state corresponding to internal processes: "it is horrible to feel like this", or to suppression of behavior: "I literally paralyze myself".

It is the responsibility of the therapist to demonstrate the action of aversive events in the client's life and lead them to discriminate how such events acquire aversive functions. According to IDC-10 (WHO, 1993), the term agoraphobia refers to the fear of leaving the house, fear of public places, fear of crowds or the fear of travelling alone on trains, cars, buses or planes [2]. The lack of a way out or available help is a key aspect of the disorder. It is the most incapacitating of the phobic disorders, causing some patients to remain completely confined at home. In the absence of effective treatment, agoraphobia frequently becomes chronic.

According to Fyer \& Coplan [3], the prevalence of agoraphobia in the general population during life is 2.5 to $6.5 \%$. In clinical populations, agoraphobia is almost never seen without a concurrent history of panic attacks or panic disorder.

\section{Formulation of the case}

Brief case description: The patient is a 62 year old accountant who owns and runs a small accounting business. He likes having things under control and well defined. He reports a desire to travel by plane, which he has never managed to do due to fear. He is married to a patient wife who always provides assistance. They have two children that no longer live with them, as they live with their respective partners. Due to his age and having an easier schedule, he feels more necessity to break this barrier and be able to travel and know places he would no longer go to by car. It is important to emphasize that the supposed fear that he reports goes beyond the barrier of planes, also including fears such as elevators and high places [4].

Initial experiences: The patient suffered a difficult childhood, with his parents working hard to pay for his studies, without the financial conditions to buy much beyond what was necessary to feed him and his brothers. When he was a child he had the desire to have a good job, a more comfortable home and to provide his future children with things that he was not able to receive from his parents. 


\section{Central beliefs}

"I won't be able to stay there with the door closed."

"I need to know how to get out."

\section{Intermediate beliefs}

"I won't feel well."

"I won't have control."

"I need to know how everything will be."

\section{Strategies of the patient}

He never takes the elevator alone or when it is very full, in which case he takes the stairs. When travelling by car he takes a route that avoids high places. In regard to airplanes he has no strategies and no excuses not to take a flight.

\section{Behavior maintainer}

As he always has to be in control of everything; the business, the family, himself; his maintainer is control; being aware of and understanding everything that is happening.

\section{Event}

The landmark event in relation to this case occurred in his adolescence at a football match at the Maracanã stadium, where, to maintain the groups of fans in order, the exits werelocked. He felt imprisoned, without a way out, becoming desperate and feeling awful. He remembers that since that day he has always worried about finding the exit, and about knowing that he could come and go. Recently he didn't feel well inside his car on the Rio-Niterói Bridge, experiencing various symptoms such as tachycardia and tensed muscles, which is when he realized that he really needed help [5].

\section{Symptoms}

Dry mouth, tachycardia, tingling, hot flushes, tensing of the muscles.

\section{Automatic thoughts}

"I have to take care of everything."

"I mustn’t be foolish."

\section{Emotions}

Sadness, fear, anguish and anxiety.

\section{Behavior}

Paralysis faced with what is desired; searches for a way to have more time so as not to resolve the situation (avoidance).

\section{Consequence}

Delay in seeking and accepting help Paralysis faced with what is desired; searches for a way to have more time so as not to resolve the situation (avoidance).

\section{List of problems reported by the patient}

I need to use the elevator without fear, as the office is on the tenth floor.

I really want to travel with my family without thinking that we are going to fall from high places, leaving them in a panic.

I would like to know a little of the world, as I have worked so much and have the financial resources to travel.

\section{Strategies}

As he does not know how to deal with these situations, he has resorted to psychotherapy on the recommendation of a close personal friend. Despite still disbelieving, he resolved to accept the recommendation and try this alternative to remove his discomfort. In the first session together we questioned alternatives, his thoughts and beliefs on how we might develop the treatment.

\section{Text on the Case}

The patient arrives with the complaint of not being able to take the elevator, problems driving through high places and having the desire but never having been able to travel by plane. He had already considered seeking psychological help, but had put it off as he thought it wasn't necessary and didn't think it would be of great value. After having a panic attack in the car while crossing the Rio-Niterói Bridge, tensing up his muscles and experiencing tachycardia and excessive sweating, remaining paralyzed and taking a long time to return to a relaxed state, he realized that he would need help. It was discussed in depth how much the patient desired to improve, what would change, what the gains would be, how affective he believed it would be and how dedicated he would be. Strategic planning for the treatment was then started, commencing with psycho education on what constitutes fear, phobia and panic attack, what cognitive behavior therapy is, and desensitization. It is worth emphasizing that he has a strong memory that all this began when he was at a football match in the Maracanã stadium and felt imprisoned and suffocated at not being able to exit the stadium. His profession is in the area of accountancy, working in a managerial role in an accountancy office. He often reports the anxiety in his thoughts: "I need to know I can get out". His principal symptoms are dry mouth, tachycardia, tingling sensation, hot flushes and tensing of the muscles. The exercises were the strong point of the case, given that they created a new perception on what he thought, reconstructing his belief in impossibility. The first step to be overcome was the elevator, which was upsetting him greatly as he had to take an elevator every day. Subsequently, we moved on to doing exercises for high places, before coming to underground trains, which were not the focus, but he hadn't used them for some years and they were good training for the airplane in terms of lack of control of the door and the opportunity to remain 
seated and relaxed, gradually increasing the number of stations that the train passed.

\section{Activities performed in the clinical case}

All the activities carried out in the case, which were essential for the efficacy of the treatment, are listed below, and divided by cognitive technique and behavioral technique [6].

\section{Results}

With the use of desensitization and performance of the various activities described in the tables $1 \& 2$ above, a great improvement was perceived. The patient reported no longer having problems taking the elevator and that his discomfort with high places had been greatly reduced.

Table 1

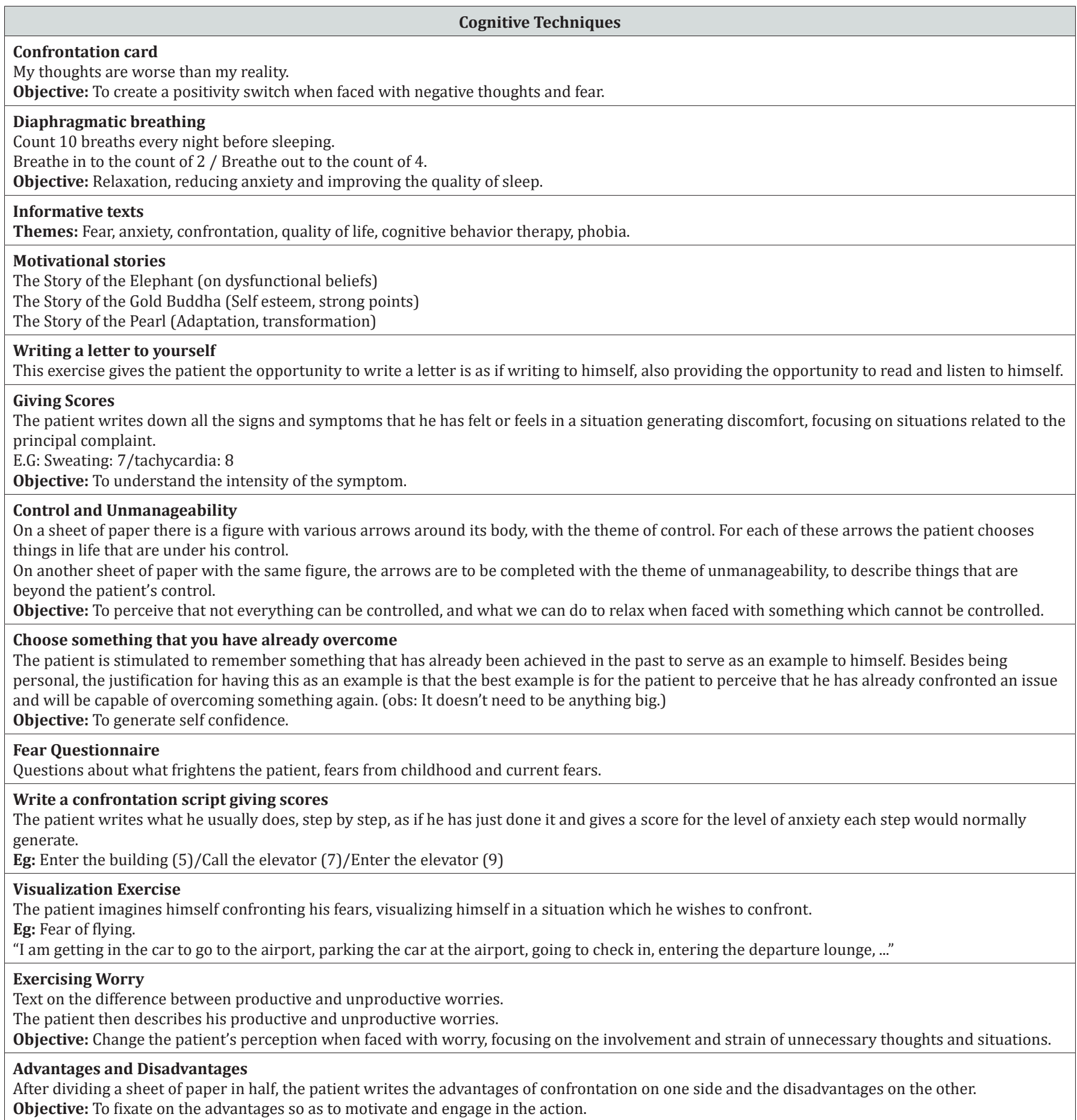


How would the patient describe a stressor situation:

Objective: To obtain the maximum amount of information on the patient's level of anxiety and what is linked to these events.

Self-feedback questions

How much have you already improved? How do you see your development?

Neutralizing Thoughts

The patient creates phrases that bring tranquility and security.

\section{Self-sabotage}

During this session, the patient considers what he believes it is that sabotages moving forward and writes it down.

The patient is asked what advice he would give to a person that is going through the same thing as him.

Motivational phrase for the week

Short motivational phrases that will be repeated many times during the day to keep determination alive.

Make your own tourist guide

The patient chooses a place he would like to visit, anywhere in the world, researches what can be done there, the best time to go, daytrips,

restaurants and what would be unforgettable about this trip?

Objective: To create the desire to confront the fear, opening up to a new world of travel!

Make an orientation card

On the plane all the seats have a card on how to put the seat belts and oxygen masks on. The idea of the orientation card is similar, but gives tips on feeling relaxed, such as breathing exercises, paying attention to emotional control, a motivational phrase, a game of spot the mistake, crosswords, the phrase from the confrontation card from the beginning of treatment and body relaxation exercises.

\section{Table 2}

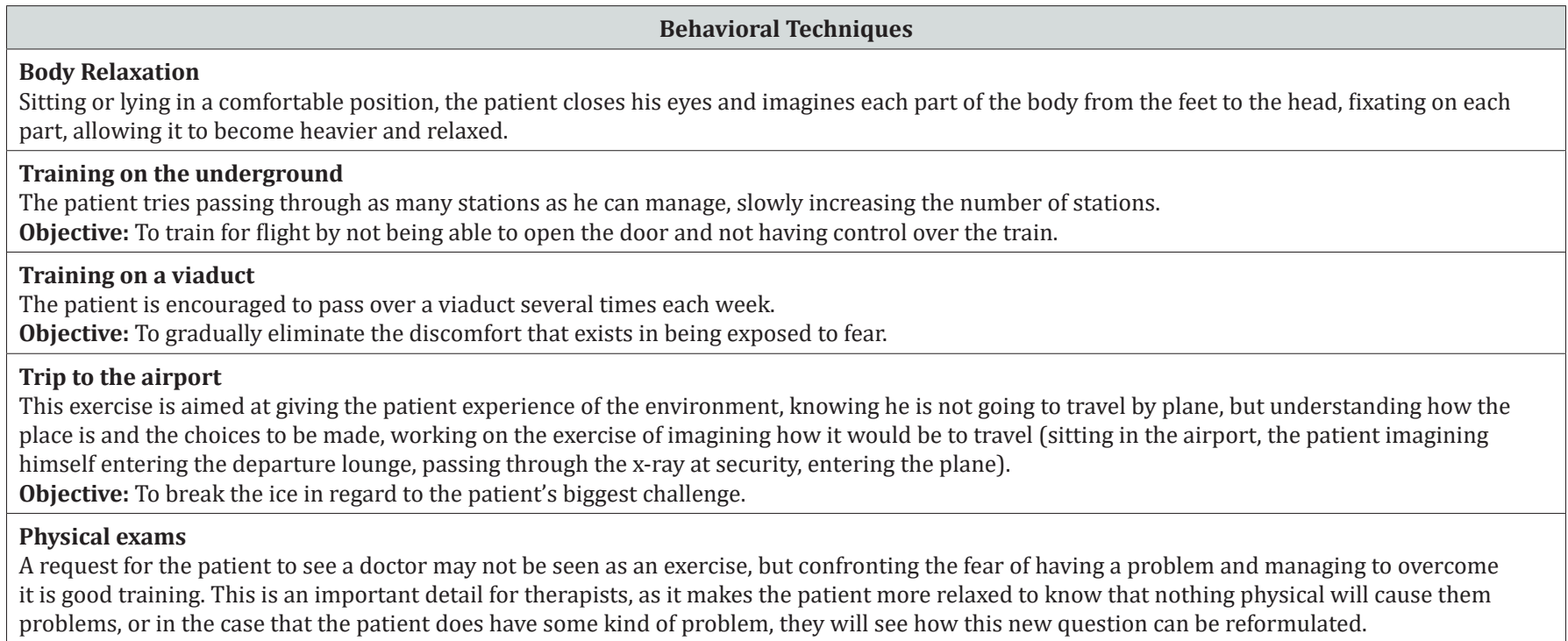

In the second session after triage, Beck's Anxiety Inventory was applied, with a result equivalent to 60 points (demonstrating an extremely concerning level of anxiety). After twenty sessions the inventory was applied again, with a significant improvement, the result having been 15 points (demonstrating a low level of anxiety) [7].

The patient made his first short flight (Rio-São Paulo), together with his wife and in the company of the therapist, which involved a great deal of work and motivation. The therapy sessions were increased to twice weekly one month before the flight, in order to increase the patient's determination and confidence. On the day of the flight many techniques were used such as relaxation, positive thinking and occupying idle time. The trip was a great success with the patient remaining calm and relaxed until landing, full of joy and pride at having overcome something he had desired for over 50 years. A new target of repeating the flight without the therapist was established in order to continue this action of confrontation and desensitization.

Consequently, it can be concluded that the more opportunities the patient has to be in contact with that which he desires to confront, the lower his discomfort becomes, as a result this generates the security to repeat the action.

It can be observed that this demonstrates that reinforcing the confrontation behavior brings the security and confidence required to achieve the desired results, with the assistance of the techniques and the application of Beck's inventory [8].

\section{Conclusion}

It was concluded that the technique of systematic desensitization is effective, in both the applied activities and 
Beck's Anxiety Inventory, which reinforces that cognitive behavior therapy brings these techniques as a construct that assists in perception, motivation, attention and engagement of the patient in the treatment. It also reinforces the possibility of formulation of the case as a solid structure for therapeutic strategies and defined goals within an agreement framework with the patient. The case study presented here illustrates the typical behavior of a person who avoids situations which evoke unpleasant bodily sensations. The procedures used were effective in teaching the patient to reduce and manage such sensations.

The patient learned to discriminate his negative emotional states, as well as the detailed process of his own reaction when in these states. He also learned to reduce the associated physiological responses and commemorated each step that was accomplished, taking more and more control of his problems.

\section{References}

1. Bașoğlu M, Marks IM, Kiliç C, Swinson RP, Noshirvani H, et al. (1994) Relationship of panic, anticipatory anxiety, agoraphobia and global improvement in panic disorder with agoraphobia treated with alprazolam and exposure. Br J Psychiatry 164(5): 647-652.
2. Fava GA, Zielezny M, Savron G, Grandi S (1995) Long-term Effects of Behavioral Treatment for Panic Disorder with Agoraphobia. Br J Psychiatry 166(1): 87-92.

3. Fyer AJ, Mannuzza S, Coplan JD (1999) Transtorno de Pânico e Agorafobia. Em Kaplan HI, Sadock BJ Tratado dePsiquiatria-Volume 2.6, Artes Médicas, Porto Alegre, Brazil.

4. Gelder MG, Marks IM (1966) Severe Agoraphobia: A Controlled Prospective Trial of Behaviour Therapy. British Journal of Psychiatry 112(484): 309-319.

5. Ghosh A, Marks IM (1987) Self-treatment of Agoraphobia by Exposure. Behavioral Therapy 18: 03-16.

6. Jansson L, Õst LG (1982) Behavioral Treatments for Agoraphobia: An Evaluative Review. Clinical Psychology Review 2: 311-336.

7. O’Brien GT, Barlow DH (1984) Agoraphobia. In: Em Turner SM (Ed.), Behavioral Treatment of Anxiety Disorders. Plenum Press, New York, USA.

8. Organização Mundial de Saúde (1993) Classificação de Transtornos Mentais e de Comportamento da CID-10: Descrições Clínicas e Diretrizes Diagnosticas. Artes Médicas, Porto Alegre, Brazil.

\section{Your next submission with Juniper Publishers will reach you the below assets}

